\title{
Uji Validitas dan Reliabilitas Kuesioner Kebutuhan Informasi Caregivers Keluarga (K-KICK)
}

\author{
Sri Rahayu ${ }^{1 *}$, Teti Rahmawati ${ }^{2}$ \\ ${ }^{1}$ Dosen Program Studi Ilmu Keperawatan Sekolah Tinggi Ilmu Kesehatan Jayakarta \\ ${ }^{2}$ Dosen Program Pendidikan Profesi Ners Sekolah Tinggi Ilmu Kesehatan Jayakarta \\ Jalan Raya PKP, Kel. Kelapa Dua Wetan, Kel. Ciracas, Kec. Jakarta Timur, Kode Pos: 13730 \\ *correspondence author: Handphone: 082136416441, E-mail: srirahayu1903@.gmail.com
}

DOI: $\underline{\text { https://doi.org/10.33859/dksm.v10i2.513 }}$

\begin{abstract}
Abstrak
Latar Belakang: Kebutuhan informasi caregivers keluarga sampai sejauh ini belum teridentifikasi secara jelas. Namun, belum ada sebuah instrumen yang mampu mengukur kebutuhan tersebut di Indonesia.

Tujuan: untuk mengukur validitas dan reliabilitas kuesioner kebutuhan informasi caregivers keluarga. Metode Penelitian: Validasi konten atau content validity index (CVI) yang melibatkan 5 orang ahli dan reliabilitas dengan alpha Cronbach digunakan dalam penelitian ini. Sejumlah 28 orang caregivers keluarga terlibat dalam uji reliabilitas.

Hasil: Kuesioner kebutuhan informasi caregivers keluarga (K-KICK) dinyatakan valid dengan nilai mean I-CVI 0,97 dan reliabel dengan alpha Cronbach 0,89. Oleh dari itu, kuesioner ini dapat digunakan untuk penelitian selanjutnya dengan populasi yang sama atau berbeda dengan jumlah sampel yang lebih besar.

Kata kunci: uji validitas, reliabilitas, kebutuhan informasi, K-KICK, caregivers keluarga
\end{abstract}

\section{Validity and Reliability Test of the Questionnaire “Kuesioner Kebutuhan Informasi Caregivers Keluarga (K-KICK)"}

\begin{abstract}
BACKGROUND: The informational needs of family caregivers until now have not been identified clearly. However, there is no instrument available to measure these needs in Indonesia.

OBJECTIVE: To measure the validity and reliability of the questionnaire information needs of family caregivers.

METHODS: Content validity test (CVI) involving 5 experts and reliability using Cronbach alpha were used in this study. A total of 28 family caregivers were involved in the reliability test.

RESULTS: The questionnaire "Kuesioner kebutuhan informasi caregivers keluarga (K-KICK)" was declared valid with a mean I-CVI of 0.97 and reliable with Cronbach's alpha 0.89. Finally, this questionnaire can be used in further studies with the same or different populations and with larger sample size.

Keywords: validity test, reliability, informational needs, $K$-KICK, family caregivers
\end{abstract}




\section{Pendahuluan}

Caregivers memiliki peranan yang sangat besar dalam perawatan pasien dengan penyakit kronis (National Alliance for Caregiving \& AARP, 2015). Data menunjukkan bahwa sekitar 90\% perawatan kepada pasien dilakukan oleh keluarga (Collins \& K Swartz, 2011; Swartz, \& Collins, 2019). Menurut beberapa hasil penelitian menjelaskan bahwa sebagian besar caregivers adalah keluarga, yaitu pasangan pasien (Ikawati, 2015; National Alliance for Caregiving \& AARP, 2004; Rahayu, 2017; Rahayu \& Rahmawati, 2019). Secara logika, hal ini tentu benar karena pasanganlah yang selalu menemani dan mendampingi pasien. Selain itu, keluarga juga mengetahui secara detail status kesehatan pasien (Gillick, 2014; Swartz, K., \& Collins, 2019). Namun, keluarga juga memiliki berbagai permasalahan, hambatan, kesulitan, dan kebingungan untuk dapat memberikan perawatan yang terbaik bagi pasien.

Perawat dan petugas kesehatan lainnya dapat secara bersama-sama mencari solusi dari permasalahan yang dihadapi oleh caregivers keluarga. Salah satu cara yang dapat dilakukan oleh perawat adalah dengan mengidentifikasi kebutuhan informasi caregivers keluarga (Etemadifar, Shahriari, Farsani, \& Bahrami, 2014). Akan tetapi, sampai sejauh ini belum ada kuesioner yang dapat digunakan untuk mengidentifikasi kebutuhan tersebut di Indonesia.

Pada penelitian ini, peneliti mengambil konsep dasar kuesioner "Informational needs" yang terdapat dalam (National Alliance for Caregiving \& AARP, 2004). Kuesioner ini terlebih dahulu diterjemahkan, disesuaikan dengan budaya Indonesia, dan ditambahkan dengan beberapa pertanyaan. Oleh karena itu, tujuan dari penelitian ini adalah untuk mengukur uji validitas dan reliabilitas kuesioner kebutuhan informasi caregivers keluarga.

\section{Bahan dan Metode}

Penelitian ini telah mendapatkan surat lolos uji etik dengan nomor surat: No SK-218/UN2.F12.D1.2.1/ETIK.FIK.2019 dari 
Komite Etik Fakultas Ilmu Keperawatan

Universitas Indonesia. Metode penelitian yang digunakan dalam penelitian ini adalah penelitian kuantitatif yaitu dengan uji instrumen. Kuesioner yang diberi nama kuesioner kebutuhan informasi caregivers keluarga (KKICK) ini terdiri dari 20 pertanyaan yang menggunakan 5 skala Likert mulai dari 0 "tidak penting", 1 “agak penting”, 2 "ragu-ragu", 3 "penting", dan 4 "sangat penting". Kebutuhan informasi semakin penting jika skornya semakin tinggi.

Uji validitas yang digunakan adalah validitas konten dengan menghitung Content Validity Index (CVI). CVI dihitung dari nilai yang diberikan oleh para ahli dengan menggunakan 4 skala Likert yaitu 1 "tidak relevan", 2 "relevan", 3 "relevan", dan 4 "sangat relevan” (Polit \& Beck, 2006). Para ahli yang dilibatkan yaitu dua orang dosen dengan pendidikan S2 Keperawatan, 1 perawat senior di Rumah Sakit Hasan Sadikin Bandung, 1 perawat senior di Rumah Sakit Gunung Jati Kota Cirebon, dan 1 orang ahli teknologi informasi dan komunikasi (TIK). Satu orang ahli TIK dilibatkan untuk memberikan penilaian karena ada beberapa pertanyaan yang memerlukan pendapat dari ahli TIK.

Uji reliabilitas kuesioner ini dilakukan pada 28 caregivers keluarga dengan alpha Cronbach. Secara teori nilai alpha Cronbach minimal 0,60 untuk dapat diterima (Cronbach, 1951).

\section{Hasil}

\section{Karakteristik Caregivers Keluarga}

Karakteristik caregivers keluarga dalam penelitian ini adalah rata-rata berusia $46,43 \pm 16,72$. Pada tabel 1 menunjukkan bahwa sebagian besar perempuan yaitu sejumlah 21 orang $(75,0 \%)$, memiliki tingkat pendidikan sekolah menengah sejumlah 15 orang $(53,6 \%)$, bekerja sejumlah 18 orang $(64,3 \%)$, dan memiliki hubungan sebagai istri pasien sejumlah 11 orang $(39,3 \%)$. 
Dinamika Kesehatan Jurnal Kebidanan dan Keperawatan Vol 10 No. 2 Desember 2019 (ISSN: 2086-3454 EISSN: 2549-4058)

url: http://ojs.dinamikakesehatan.unism.ac.id DOI : https://doi.org/10.33859/dksm.v10i2

Uji Validitas dan Reliabilitas Kuesioner Kebutuhan Informasi Caregivers Keluarga (K-KICK)

\begin{tabular}{|c|c|c|c|}
\hline \multirow{2}{*}{$\begin{array}{l}\text { Tabel } \\
\text { No }\end{array}$} & \multicolumn{3}{|c|}{$\begin{array}{l}\text { 1. Distribusi Frekuensi } \\
\text { Caregivers Keluarga Dari } \mathrm{P} \\
\text { Penyakit Kronis }(\mathrm{n}=28)\end{array}$} \\
\hline & $\begin{array}{l}\text { Karakteristik } \\
\text { Caregivers Keluarga }\end{array}$ & $\begin{array}{c}\text { Jumlah } \\
(f)\end{array}$ & $\begin{array}{c}\text { Persentase } \\
(\%)\end{array}$ \\
\hline \multirow[t]{3}{*}{1} & Jenis Kelamin & & \\
\hline & Laki-laki & 7 & 25,0 \\
\hline & Perempuan & 21 & 75,0 \\
\hline \multirow[t]{4}{*}{2} & Tingkat Pendidikan & & \\
\hline & Perguruan Tinggi & 11 & 39,3 \\
\hline & Sekolah Menengah & 15 & 53,6 \\
\hline & Sekolah Dasar & 2 & 7,1 \\
\hline \multirow[t]{3}{*}{3} & Pekerjaan & & \\
\hline & Bekerja & 18 & 64,3 \\
\hline & Tidak Bekerja & 10 & 35,7 \\
\hline \multirow[t]{5}{*}{4} & $\begin{array}{l}\text { Hubungan dengan } \\
\text { Pasien }\end{array}$ & & \\
\hline & Suami & 5 & 17,9 \\
\hline & Istri & 11 & 39,3 \\
\hline & Anak & 9 & 32,1 \\
\hline & Saudara kandung & 3 & 10,7 \\
\hline
\end{tabular}

\section{Uji Validitas dan Reliabilitas}

Pada tabel 2 menunjukkan bahwa hasil uji validitas konten menunjukkan valid dengan nilai mean I-CVI sebesar 0,97. Sedangkan untuk setiap pertanyaan menunjukkan nilai I-CVI mulai dari 0,80 sampai dengan 1,00 . Sehingga didapatkan nilai Scale-CVI/Universal Agreement (S-CVI/UA) sebesar 0,85.

Hasil uji reliabilitas yang dilakukan pada 28 orang caregivers keluarga dari pasien dengan penyakit kronis menunjukkan reliabel dengan nilai alpha Cronbach sebesar 0,89. Nilai ini 
Dinamika Kesehatan Jurnal Kebidanan dan Keperawatan Vol 10 No. 2 Desember 2019 (ISSN: 2086-3454 EISSN: 2549-4058)

url: http://ojs.dinamikakesehatan.unism.ac.id DOI : https://doi.org/10.33859/dksm.v10i2

Uji Validitas dan Reliabilitas Kuesioner Kebutuhan Informasi Caregivers Keluarga (K-KICK)

Tabel 2. Content Validity Index (CVI) Kuesioner Kebutuhan Informasi Caregivers Keluarga (K-KICK)

\begin{tabular}{|c|c|c|c|c|c|c|c|c|}
\hline No & Pertanyaan/ Peryataan isi kuesioner & Ahli 1 & Ahli 2 & Ahli 3 & Ahli 4 & Ahli 5 & $\begin{array}{c}\text { Jumlah } \\
\text { Kesepakatan }\end{array}$ & I-CVI \\
\hline 1. & Mengetahui tentang penyakit pasien & 4 & 4 & 4 & 4 & 4 & 5 & 1,00 \\
\hline 2. & $\begin{array}{l}\text { Memahami program pengobatan yang } \\
\text { harus dijalani pasien }\end{array}$ & 4 & 4 & 4 & 4 & 4 & 5 & 1,00 \\
\hline 3. & Memahami kegunaan obat-obatan pasien & 3 & 4 & 4 & 4 & 4 & 5 & 1,00 \\
\hline 4. & $\begin{array}{l}\text { Mengetahui cara untuk mengendalikan } \\
\text { gejala yang muncul pada pasien }\end{array}$ & 4 & 4 & 4 & 3 & 4 & 5 & 1,00 \\
\hline 5. & $\begin{array}{l}\text { Mendapat informasi tentang cara } \\
\text { perawatan pasien di rumah }\end{array}$ & 3 & 3 & 4 & 3 & 4 & 5 & 1,00 \\
\hline 6. & $\begin{array}{l}\text { Mendapat informasi tentang managemen } \\
\text { perubahan gaya hidup yang harus } \\
\text { dilakukan oleh pasien }\end{array}$ & 3 & 4 & 4 & 3 & 4 & 5 & 1,00 \\
\hline 7. & $\begin{array}{l}\text { Memahami aktivitas fisik yang boleh } \\
\text { dilakukan oleh pasien }\end{array}$ & 4 & 4 & 4 & 3 & 4 & 5 & 1,00 \\
\hline 8. & Merencanakan perawatan jangka panjang & 3 & 3 & 4 & 3 & 4 & 5 & 1,00 \\
\hline 9. & $\begin{array}{l}\text { Program edukasi tentang cara perawatan } \\
\text { pasien yang benar }\end{array}$ & 4 & 4 & 4 & 3 & 4 & 5 & 1,00 \\
\hline 10. & Program edukasi tentang diet pasien & 4 & 4 & 4 & 3 & 4 & 5 & 1,00 \\
\hline 11. & $\begin{array}{l}\text { Program pelatihan pengukuran tekanan } \\
\text { darah }\end{array}$ & 3 & 3 & 3 & 2 & 4 & 4 & 0,80 \\
\hline 12. & $\begin{array}{l}\text { Memenuhi kebutuhan hidup sehari-hari } \\
\text { pasien }\end{array}$ & 3 & 4 & 3 & 2 & 4 & 4 & 0,80 \\
\hline 13. & Memenuhi kebutuhan spiritual pasien & 4 & 3 & 4 & 3 & 4 & 5 & 1,00 \\
\hline 14. & $\begin{array}{l}\text { Meminta bantuan orang lain untuk } \\
\text { merawat pasien jika diperlukan }\end{array}$ & 3 & 3 & 2 & 3 & 4 & 4 & 0,80 \\
\hline 15. & $\begin{array}{l}\text { Membantu pasien untuk beradaptasi } \\
\text { dengan kondisi kesehatannya }\end{array}$ & 4 & 4 & 4 & 4 & 4 & 5 & 1,00 \\
\hline 16. & $\begin{array}{l}\text { Meningkatkan kemampuan pasien untuk } \\
\text { mandiri secara bertahap }\end{array}$ & 3 & 4 & 4 & 4 & 4 & 5 & 1,00 \\
\hline 17. & $\begin{array}{l}\text { Mengetahui cara membantu pasien untuk } \\
\text { bersosialisasi dengan lingkungan }\end{array}$ & 3 & 4 & 4 & 4 & 4 & 5 & 1,00 \\
\hline 18. & $\begin{array}{l}\text { Mendapat kesempatan untuk berbicara } \\
\text { dengan beberapa orang yang mengalami } \\
\text { hal yang sama dalam sebuah group }\end{array}$ & 4 & 4 & 4 & 4 & 4 & 5 & 1,00 \\
\hline 19. & $\begin{array}{l}\text { Mendapat informasi tentang perawatan } \\
\text { pasien dari sebuah group }\end{array}$ & 4 & 4 & 3 & 4 & 4 & 5 & 1,00 \\
\hline 20. & $\begin{array}{l}\text { Mendapat informasi tentang perawatan } \\
\text { pasien dari website yang terpercaya }\end{array}$ & 3 & 3 & 3 & 4 & 4 & 5 & 1,00 \\
\hline \multirow{2}{*}{\multicolumn{2}{|c|}{ Proporsi Relevansi }} & & & & & & Mean I-CVI & 0,97 \\
\hline & & 1,00 & 1,00 & 0,95 & 0,90 & 1,00 & $\begin{array}{l}\text { S-CVI/UA } \\
\text { S-CVI/Ave }\end{array}$ & $\begin{array}{l}0,85 \\
0,97\end{array}$ \\
\hline
\end{tabular}




\section{Pembahasan}

\section{Karakteristik Caregivers Keluarga}

Karakteristik caregivers keluarga pada penelitian ini berusia rata-rata 46 tahun. Usia ini termasuk kategori usia lansia awal (Depkes RI, 2009). Rentang usia caregivers keluarga ini juga disebutkan dalam National Alliance for Caregiving \& AARP (2009) yang menyebutkan bahwa usia caregivers yaitu 49 tahun. Usia serupa sekitar 47-48 tahun juga ditemukan pada penelitian lain (Rahayu, 2017; Rahayu \& Rahmawati, 2019). Hal ini menjelaskan bahwa orang yang merawat pasien yaitu caregivers sejalan dengan usia pasien dimana dengan bertambahnya usia, seseorang beresiko untuk terjadinya suatu penyakit dan keluargalah yang merawatnya. Sebagian besar caregivers keluarga dalam penelitian ini adalah perempuan, istri, dan bekerja. Hal ini dikuatkan oleh penelitian lain yang menyebutkan hal yang sama (Ikawati, 2015; National Alliance for Caregiving \& AARP, 2004; Rahayu, 2017; Rahayu \& Rahmawati, 2019).

\section{Uji Validitas dan Reliabilitas}

Pada penelitian ini didapatkan hasil bahwa dari hasil pengukuran validitas dan reliabilitas menunjukkan bahwa kuesioner KKICK ini valid dan reliabel. Hasil uji validitas dengan validasi konten yang melibatkan 5 ahli memiliki nilai mean I-CVI 0,97. Hasil CVI ini dapat dikatakan sangat baik. Kuesioner K-KICK ini dapat dinyatakan valid untuk digunakan pada penelitian selanjutnya.

Beberapa penelitian di Indonesia mengukur validitas dengan CVI juga. Hasilnya sangat bervariasi, tergantung jumlah ahli yang dilibatkan dan kuesioner yang dinilai. Penelitian yang dilakukan oleh Indrayana, S., \& Fang (2019) melibatkan 2 orang ahli dengan hasil CVI yaitu 1,00. Ada juga penelitian yang hasilnya sempurna yaitu 1,00 dengan melibatkan 3 orang ahli (Rahayu, Fajarini, \& Setiawan, 2018). Waltz, C.F., Strickland, O.L., \& Lenz (2005) dan Lynn (1986) menjelaskan bahwa validasi konten minimal melibatkan 3 orang ahli. Namun, Lynn (1986) juga merekomendasikan lebih baik melibatkan lima atau enam ahli. Hal ini juga 
dilakukan oleh peneliti dalam penelitian lain dengan melibatkan 6 orang ahli dengan nilai mean I-CVI 0,93 (Rahayu \& Chen, 2019).

Uji reliabilitas dengan menggunakan Cronbach alpha pada kuesioner K-KICK ini dinyatakan reliable dengan nilai bagus yaitu 0,89. Nilai ini dapat diartikan bahwa kuesioner memiliki tingkat ketetapan yang bagus untuk digunakan pada penlitian selanjutnya (Cronbach, 1951).

\section{Kesimpulan}

Kesimpulan dari penelitian ini menunjukkan bahwa kuesioner ini dinyatakan valid dan reliabel untuk digunakan pada penelitian selanjutnya. Peneliti juga berharap bahwa kuesioner ini dapat digunakan oleh peneliti lain dengan populasi yang berbeda dengan jumlah sampel yang lebih besar.

\section{Ucapan Terima Kasih}

Penelitian ini mendapatkan sumber dana dari Kementerian Riset dan Teknologi Republik Indonesia. Peneliti mengucapkan terimakasih atas alokasi dana untuk penelitian ini dan hasilnya semoga dapat bermanfaat bagi para ilmuwan, peneliti, akademisi, dan terutama bagi masyarakat pada umumnya.

Ucapan terima kasih juga kami sampaikan kepada para ahli yang terlibat dalam penilaian CVI, RSPAD Gatot Soebroto sebagai tempat pengambilan data terkait uji reliabilitas, dan TIM Reviewer dari RSPAD Gatot Soebroto dan FIK UI yang telah banyak memberikan masukan yang membangun, Research Assistant: Mbak Wida, Yunita, Elly, dan Nurbaeti yang telah membantu dalam pengumpulan data untuk kepentingan uji reliabilitas, serta STIKes Jayakarta yang memfasilitasi penelitian ini dengan lancar. 


\section{Daftar Pustaka}

Collins, L., \& K Swartz. (2011). Caregiver care. American Family Physician, 1309. Retrieved from https://pdfs.semanticscholar.org/e43d/2b34 6b994f0043e46a2158f356bac6952466.pdf

Cronbach, L. J. (1951). Coefficient alpha and the internal structure of tests. Psychometrika, 16(3), 297-334. https://doi.org/10.1007/bf02310555

Etemadifar, S., Shahriari, M., Farsani, A., \& Bahrami, M. (2014). Informational needs and related problems of family caregivers of heart failure patients: A qualitative study. Journal of Education and Health Promotion, 3(1), 113. https://doi.org/10.4103/2277-9531.145908

Gillick, M. (2014). The Critical Role of Caregivers in Achieving. JAMA: The Journal of the American Medical Association, 2, 11-12. https://doi.org/10.1001/jama.2013.7310.C onflict

Ikawati, Z. (2015). Faktor-Faktor Yang Mempengaruhi Kualitas Hidup Pasien Gagal Jantung Kronik Factors That Influence Quality of Life in Chronic Heart Failure ( Chf ). Jurnal Keperawatan Soedirman (The Soedirman Journal of Nursing), 2015, 259-266.

Indrayana, S., \& Fang, S. Y. (2019). Validitas dan reliabilitas The Brief Illness Perception Questionnaire versi Bahasa Indonesia pada Pasien Diabetes Mellitus. Dinamika Kesehatan Jurnal Kebidanan Dan Keperawatan, 10(1).

Lynn, M. R. (1986). Determination and quantification of content validity. Nursing Research, 35, 382-385.
National Alliance for Caregiving. (2015). Caregiving in the U.S.- AARP 2015 Report. Bethesda, Md: National Alliance for Caregiving; 2015. Retrieved from https://www.aarp.org/content/dam/aarp/ppi $/ 2015 /$ caregiving-in-the-united-states2015-report-revised.pdf. Diakses pada tanggal 7 Agustus 2019

National Alliance for Caregiving, \& AARP. (2004). Caregiving in the U.S., (April), 183.

National Alliance for Caregiving, \& AARP. (2009). A Focused Look at Those Caring for Someone Age 50 or Older. Caregiving in the U.S., (November), 1-79.

Polit, D. F., \& Beck, C. T. (2006). The content validity index: Are you sure you know what's being reported? Critique and recommendations. Research in Nursing and Health, 29(5), 489-497. https://doi.org/10.1002/nur.20147

Rahayu, S. (2017). 印尼心臟衰竭病人之家屬 照顧者的衛教需求. 成功大學護理學系 學位論文，1-77. Retrieved from http://www.airitilibrary.com/Publication/al DetailedMesh?docid=U00260802201717114900

Rahayu, S., \& Chen, H. M. (2019). Penerjemahan dan validasi konten kuesioner "Educational needs of caregivers instrument" ke Bahasa Indonesia untuk caregivers keluarga pasien gagal jantung. Jurnal Ilmiah Kesehatan Keperawatan, Process In Review.

Rahayu, S., \& Fajarini, M., Setiawan, A. (2018). Content validity of Evidence Based Practice Questionnaire (EBPQ). In The 2nd International Nursing Scholars Congress, Universitas Indonesia (p. 67). 
Dinamika Kesehatan Jurnal Kebidanan dan Keperawatan Vol 10 No. 2 Desember 2019 (ISSN: 2086-3454 EISSN: 2549-4058)

url: http://ojs.dinamikakesehatan.unism.ac.id DOI : https://doi.org/10.33859/dksm.v10i2

Uji Validitas dan Reliabilitas Kuesioner Kebutuhan Informasi Caregivers Keluarga (K-KICK)

Rahayu, S., \& Rahmawati, T. (2019).

Karakteristik dan kesediaan caregivers

keluarga dari pasien kronis tentang pembentukan support group. Jurnal Ilmiah Keperawatan Altruistik, 2(2), 53-63.

Swartz, K., \& Collins, L. G. (2019). Caregiver Care. American Family Physician, 99(11).

Waltz, C.F., Strickland, O.L., \& Lenz, E. R. (2005). Measurement in nursing and health research (3rd ed.). New York: Springer Publishing Co. 